\title{
Research on Management and Control of Miners' Unsafe Behavior Based on Gray Theory
}

\author{
Shuicheng Tian $\mathbb{D}^{1},{ }^{1,2}$ Guangtong Shao $\mathbb{D}^{1,2}$ Hongxia Li ${ }^{1},{ }^{1,2}$ Pengfei Yang $\mathbb{D}^{1,2}$ \\ Qingxin Dang $\mathbb{D}^{1,2}$ and Fujing Yuan $\mathbb{D}^{1,2}$ \\ ${ }^{1}$ School of Safety Science and Engineering, Xi' an University of Science and Technology, Xi' an 710054, China \\ ${ }^{2}$ Institute of Safety and Emergency Management, Xi'an University of Science and Technology, Xi' an 710054, China \\ Correspondence should be addressed to Guangtong Shao; 18120089018@stu.xust.edu.cn
}

Received 14 September 2021; Revised 13 October 2021; Accepted 23 October 2021; Published 11 November 2021

Academic Editor: Bangbiao Wu

Copyright (c) 2021 Shuicheng Tian et al. This is an open access article distributed under the Creative Commons Attribution License, which permits unrestricted use, distribution, and reproduction in any medium, provided the original work is properly cited.

\begin{abstract}
A large number of accidents and scientific researches show that miners' unsafe behavior affects coal mine safety production seriously. In order to effectively reduce the incidence of miners' unsafe behavior, to improve their safety level, and reduce accidents caused by it, this paper used gray relational analysis method to analyze the miners' unsafe behavior of W mine and quantitatively calculated the risk value of miners' unsafe behavior. The results showed that the risk value of unsafe behavior in violation of labor discipline was 0.4358 , which was much higher than that of other miners' unsafe behaviors. Therefore, unsafe behavior in violation of labor discipline was determined as the key point of control in the next stage. Then, GM $(1,1)$ method was used to establish a predicted model for unsafe behavior, to predict the number of unsafe behaviors in violating labor discipline in next quarter, and to determine reasonable unsafe behavior control target. This study plays a driving role in controlling unsafe behaviors of miners and improving safe production water of coal mine.
\end{abstract}

\section{Introduction}

Coal resources have been the dominant energy source for our country's economic development for a long time, occupying a dominant position in the energy structure [1]. The issue of safety has always been a key task in energy development [2-5]. With the development of social economy, the level of coal mine safety production in our country has been continuously improved in the past decade, and the decline in accident-related indicators has tended to be flat, reaching a stage where it is difficult to reduce significantly [6]. Therefore, the industry needs to comprehensively consider all factors and find new breakthroughs. Human factors are of great significance to safe production. Many studies and data analyses have shown that human factors are the main factor that punish risks and cause accidents [7]. Studies have shown that more than $85 \%$ of mine accidents are caused by human factors [8]. It can be seen that, with the advancement of science and technology and the increasing reliability of technology and equipment, employees have gradually became the main perpetrators of accidents in the entire production system [9].

Gerard and Shaw [10] proposed a planned behavior theory to prevent unsafe behavior. Rafiq [11] conducted unsafe behavior control through safety objective management method and finally achieved a leap from $86 \%$ to $92.9 \%$. Mohammad et al. and Brian et al. [12] provided a reference for the behavioral safety design and construction of the building trades by studying and rethinking the construction cases in the future. Leyla et al. [13] proposed a service behavior model through functional behavior analysis and conducted behavioral safety design to reduce unsafe behavior. Wu et al. [14] constructed the unsafe behavior cause model based on the theory of planned behavior, combined with the general process of behavior output perception, decision-making, and postdecision implementation. Wang et al. [15] compared the effects of several safety training methods through a random-effects negative binomial model, 
thus selecting the most effective training methods to reduce driver risk-taking behavior. Li et al. [16] built a proactive behavior-based safety model through virtual construction simulation to control construction workers' unsafe behavior.

The basic idea of the gray relational analysis model is to judge whether the connection between different sequences is close according to the geometric shape of the sequence curve. Twala et al. [17] used the gray relational classifier algorithm to model and analyze road traffic accident data in Gauteng Province, South Africa. Xia et al. [18] used the gray relational analysis model to study the relationship between rolling bearing processing quality and vibration and found that the structural dimensional error parameters have a greater impact on bearing vibration. Dong et al. [19] proposed a gray relational fuzzy clustering algorithm, which effectively integrates troubleshooting experience and multifactor decision-making algorithms to select troubleshooting methods, improving the level of expert systems and the efficiency of aircraft troubleshooting. In the era of big data, the gray system forecasting method based on small data mining has emerged, and it has become an effective tool for people to extract valuable information from massive data. Chirwa et al. [20], based on data from the United Kingdom and the United States, used the GM $(1,1)$ model to estimate the risk of car accidents; Cemple [21] used a gray prediction model to monitor the vibration state of machinery; Hao et al. $[22,23]$ used a gray system model to analyze the hydrological process in karst basin. After analyzing and predicting, they have obtained high accuracy. They also used the segmented gray model to study the impact of human activities on the hydrological process of the karst basin.

Through literature review, we found that the existing research on unsafe behavior is more in the field of construction or driving, while there is less research on unsafe behavior of coal miners. Meanwhile, many researches are aimed at the influencing factors of unsafe behaviors, or the precontrol of unsafe behaviors in a special environment. However, the gray relational theory and gray prediction model are used in the analysis of certain influencing factors or the prediction of natural phenomena. This paper took $\mathrm{W}$ coal mine as the research object, using gray correlation analysis method to analyze and filter unsafe behaviors of employees and use gray correlation to describe the relationship between unsafe behaviors. Then, we use the gray prediction system to predict the number of unsafe behaviors with higher risk values and optimize the model to improve the accuracy of the prediction. This provides a basis for $\mathrm{W}$ coal mine to control unsafe behaviors in a targeted manner.

\section{Methods}

The unsafe behavior management and control are in primary stage. Whether an employee can report unsafe behavior voluntarily will be affected by subjective actors, such as experience and psychology. And it is difficult to make the data in detail. The unsafe behavior data obtained may be only a part of all unsafe behaviors, and there are many different types for unsafe behavior. Taking into account the above reasons, this paper chooses gray relational analysis method as the analysis method of unsafe behavior samples.

The number of unsafe behaviors reflects the identification and control of unsafe behaviors in the previous period and also determines the future development trend of unsafe behaviors in the working area [24]. Manual records will have errors; the number of unsafe behaviors shows volatility. However, they are consistent all in all; the number of unsafe behaviors' increases, decreases, or stabilizes with the ability of identifying control. Therefore, the number of unsafe behaviors is regular and predictable. This paper uses mean GM $(1,1)$ prediction model to predict the number of unsafe behaviors.

2.1. Gray Relational Analysis. Generally speaking, the more the statistical data, the more accurate the information expressed. Insufficient data may lead to deviations in the analysis results. There are many difficulties in the statistics of unsafe behaviors of employees, such as whether miners can report voluntarily or whether managers can accurately record them, which will affect the accuracy of unsafe behavior statistics. Taking into account the above reasons, this study selects the gray correlation analysis method [25] as the analysis method of unsafe behavior samples. Compared with regression analysis and correlation analysis, gray correlation analysis does not require high sample size, which can be as few as four. It has no requirements for the law of data. It can handle irregular data, and the amount of calculation is not large. When the quantitative results are inconsistent with the qualitative results, the characteristics of the data are analyzed to reveal the law of its evolution [26].

All in all, the unsafe behaviors of employees in the enterprise show a certain change trend, and the gray correlation analysis can carry out a quantitative analysis of the change situation, that is, a quantitative comparative analysis of the change situation. Through the analysis of multiple factors in the gray system, in the process of its development, based on the sample data of each factor, the gray correlation degree is used to describe the strength, size, and order of the relationship between the factors, according to the factors and the research system. The change trend and numerical relationship between the arrays of factors are used to measure the degree of correlation between factors. If the sample data reflects that the development direction and speed of the two factors are closer, the degree of correlation between them is greater and the degree of influence is greater; if the degree of correlation is smaller, the degree of influence is less.

\subsubsection{Determine the Variable Sequence and the Reference} Sequence. The sequence that reflects the system behavior characteristics is determined as the reference sequence, and the sequence that affects the system behavior is the variable sequence; the reference sequence is expressed as $X_{0}^{\prime}$, the variable sequence is expressed as $X i(i=1,2,3, \ldots . ., n)$, and the specific form can be described by the following matrix: 


$$
X^{\prime}=\left[\begin{array}{cccc}
X_{0}^{\prime}(1) & X_{1}^{\prime}(1) & \cdots & X_{n}^{\prime}(1) \\
X_{0}^{\prime}(2) & X_{1}^{\prime}(2) & \cdots & X_{n}^{\prime}(2) \\
\cdots & \cdots & \cdots & \cdots \\
X_{0}^{\prime}(N) & X_{1}^{\prime}(N) & \cdots & X_{n}^{\prime}(N)
\end{array}\right] .
$$

Among them,

$$
X_{i}^{\prime}=\left[X^{\prime} i(1), X^{\prime} i(2), \ldots, X^{\prime} i(N)\right]^{T}, \quad i=0,1,2, \ldots n .
$$

$N$ is the length of the sequence.

The original data in the system has different dimensions and orders of magnitude, which is not inconvenient to compare directly. Therefore, in order to ensure the correctness of comparison among different sequences, the data should be dimensionless in gray relational analysis method. This study used the average method to dimensionalize the data:

$$
X_{i}(k)=\frac{X_{i}^{\prime}(k)}{1 / N \sum_{k=1}^{N} X_{i}^{\prime}(k)} .
$$

Turn the matrix into

$$
X=\left[\begin{array}{cccc}
X_{0}(1) & X_{1}(1) & \cdots & X_{n}(1) \\
X_{0}(2) & X_{1}(2) & \cdots & X_{n}(2) \\
\cdots & \cdots & \cdots & \cdots \\
X_{0}(N) & X_{1}(N) & \cdots & X_{n}(N)
\end{array}\right] .
$$

This paper calculated the differential value between all items of data in the variable sequence and the data in its corresponding reference sequence and took the absolute value of the difference:

$$
\Delta_{i}(k)=\left|X_{0}(k)-X_{i}(k)\right| .
$$

And the difference matrix is

$$
\Delta X=\left[\begin{array}{cccc}
\Delta_{1}(1) & \Delta_{2}(1) & \cdots & \Delta_{n}(1) \\
\Delta_{1}(2) & \Delta_{2}(2) & \cdots & \Delta_{n}(2) \\
\cdots & \cdots & \cdots & \cdots \\
\Delta_{1}(N) & \Delta_{2}(N) & \cdots & \Delta_{n}(N)
\end{array}\right] .
$$

Calculate the correlation coefficient between all items of data in the variable sequence and the data in its corresponding reference sequence:

$$
\zeta_{i}(k)=\frac{\min _{i} \min _{k} \Delta_{i}(k)+\rho \max _{i} \max _{k} \Delta_{i}(k)}{\Delta_{i}(k)+\rho \max _{i} \max _{k} \Delta_{i}(k)} .
$$

$\triangle \mathrm{i}(\mathrm{k})$ represents the absolute difference between $X 0$ and $X i$ at point $k$.

(1) $\min _{i} \min _{k} \Delta_{i}(k)$ represents minimal absolute difference.

(2) $\max _{i} \max _{k} \Delta_{i}(k)$ represents maximal absolute difference.
(3) $\rho$ represents resolution coefficient, which is a number between 0 and 1.

It is used to reduce the result distortion caused by too large value to improve the significance of the difference between relational coefficients. Generally, take $\rho=0.5$. Relational coefficient matrix is

$$
\xi=\left[\begin{array}{cccc}
\xi_{1}(1) & \xi_{2}(1) & \ldots & \xi_{n}(1) \\
\xi_{1}(2) & \xi_{2}(2) & \ldots & \xi_{n}(2) \\
\ldots & \ldots & \ldots & \ldots \\
\xi_{1}(N) & \xi_{2}(N) & \ldots & \xi_{n}(N)
\end{array}\right] .
$$

Calculate the mean of relational coefficient, according to

$$
\gamma_{i}=\frac{1}{N} \sum_{k=1}^{N} \xi_{i}(k) .
$$

2.2. Mean GM $(1,1)$ Prediction Model. Chinese scholar Deng JuLong proposed the gray system in $1982[27,28]$, which is a mathematical tool used to study problems with uncertain information and lack of data. The gray model reveals the law of system evolution by processing the original data and quantitatively predicts the future state of the system. The model is divided into $\mathrm{GM}(1,1)$ original differential gray model (ODGM), GM $(1,1)$ even gray model (EGM), GM (1, 1) discrete gray model (DGM), and GM $(1,1)$ even differential gray model (EDGM). Affected by the level of technology and management, coal mining companies have different capabilities in identifying and screening unsafe behaviors. Therefore, the number of unsafe behaviors counted at each stage of the coal mine is an oscillating sequence. Compared with the other three models, EGM is more suitable for oscillating series [29-31]. Therefore, this article chooses GM (1, 1) EGM, and its basic principle is in [32-35].

The original sequence is [36]

$$
X^{(0)}(t)=\left\{x^{(0)}(1), x^{(0)}(2), \ldots x^{(0)}(m)\right\}
$$

where $m$ is the size of samples.

For $X^{(0)}(t)$ and for $X$, do first-order accumulation to generate a sequence of sequences (1-AGO) and obtain $X^{(1)}$ $(t)$ and

$$
X^{(1)}(t)=\sum_{i=1}^{t} x^{(0)}(i) \text {. }
$$
and

Figure out the nearest neighbor mean $Z^{(1)}(t)$ of $X^{(1)}(t)$

$$
Z(1)(t)=\frac{1}{2}(x(1)(t)+x(1)(t-1)), \quad t=1,2, \ldots, m-1 .
$$

Then,

$$
x^{(1)}(t)+a z^{(1)}(t)=b .
$$


The whitening differential equation of the above equation is

$$
\frac{\mathrm{d} x^{(1)}}{\mathrm{Et}}+E^{(1)}(t)=b .
$$

The vector $\widehat{a}=[a, b]^{\mathrm{T}}$ in the equation can be determined by the least squares method; namely, $\widehat{a}=\left[B^{T} B\right]^{-1} B^{T}$ and

$$
\begin{aligned}
& \Upsilon=\left[\begin{array}{c}
x^{(0)}(2) \\
x^{(0)}(2) \\
\vdots \\
x^{(0)}(n)
\end{array}\right], \\
& B=\left[\begin{array}{c}
-z^{(1)}(2) 11 \\
-z^{(1)}(3) 11 \\
\vdots \\
11 \\
-z^{(1)}(n) 11
\end{array}\right] .
\end{aligned}
$$

In the above equation, $a$ is known as development coefficient, which reflects the development status of a variable. $b$ is known as gray actuating quantity.

Once each coefficient is figured out, gray GM $(1,1)$ prediction model is determined:

$$
\widehat{x}^{(1)}(t)=\left(x^{(0)}(t)-\frac{b}{a}\right) e^{-a(t-1)}+\frac{b}{a} .
$$

Then, inverse accumulation is made for the above equation, and the prediction value of any given input is worked out.

$$
\widehat{x}(0)=\left(1-e^{a}\right)\left(x(0)(1)-\frac{b}{a}\right) e^{-a(k-1)}, \quad k=1,2, \ldots, n .
$$

\section{Case Study}

3.1. Summary of $W$ Mine. $\mathrm{W}$ mine is a part of Shenhua Shendong Group, which was founded on December 12, 1988, and is located in Ordos City, Inner Mongolia Autonomous Region. It belongs to the north-central mine of Shenfu Dongsheng Coal Field, with an area of $44.10 \mathrm{~km}^{2}$. W mine is a modern production process with high output and high efficiency mine. More than $90 \%$ of injuries and deaths from accidents have been related to unsafe behavior over the years. In order to continue to improve the overall safety level under the existing conditions, it is necessary to strengthen the miners' unsafe behavior prevention and control.

\subsection{Risk Identification of W Miners' High-Risk Unsafe} Behavior. This paper took all the employees as the research object in $\mathrm{W}$ mine and made a statistical analysis of the unsafe behavior of employees in the fourth quarter of 2019 year. A total of 281 unsafe behaviors were recorded. However, the records of unsafe behaviors by coal mine managers are not standardized and it is difficult to make statistics. Therefore, it is necessary to filter and classify the unsafe behaviors recorded.

3.2.1. Classification of Unsafe Behavior. To classify unsafe behaviors, it is necessary to clarify the formation mechanism of unsafe behaviors of miners. Through the analysis of the influencing factors of unsafe behaviors, the mechanism model of unsafe behaviors as shown in Figure 1 is obtained. In this model, from external stimulus to behavior initiation, miners have experienced the process of stimulus perception, behavior selection, and decision-making.

In the stimulus perception stage, because of the unsafe state of the equipment or the unsafe factors in the environment, the miners' perception of the production system will be biased, leading to unsafe behaviors; in the manager's decision-making stage, when the manager's decision is biased, the miners deviations in the perception of hidden dangers may also cause unsafe behaviors; at the stage of initiating behaviors by miners, when miners consider unsafe behaviors based on their value judgments that the benefits of unsafe behaviors are higher than those of safe behaviors, it is worth taking the risk, and there will often be unsafe behaviors. Therefore, on the basis of referring to various domestic and foreign classification materials on unsafe behaviors, this article has carried out a new classification of the unsafe behaviors of employees from the perspective of motivation and divided the unsafe behaviors into three categories: unsafe behaviors caused by system deviations, unsafe behaviors caused by management deviations, and unsafe behaviors caused by behavior deviations, as shown in Figure 2 .

3.2.2. Data Analysis. According to the unsafe behavior classification standard mentioned above, the data of the unsafe behaviors collected in the $\mathrm{W}$ coal mine are classified, and a total of 281 unsafe behaviors are collected in the first quarter of 2019, 8 invalid records are removed, and a total of 273 valid unsafe behaviors are obtained. We divided these 273 unsafe behavior records into 12 categories, namely, $A$ : vehicle transportation accident, $B$ : work post on fatigue, $C$ : not standardized operation, $D$ : the preclass meeting system which is not in place, E:hazard identification being insufficient, $F$ : handover of the shift, $G$ : certificate implementation being insufficient, $H$ : poor electromechanical management, $I$ : emergency self-rescue ability which is not strong , J: one ventilation and three preventions, $K$ : violated labor discipline, and $L$ : appliances for labor protection improper use. Detailed data are shown in Table 1.

3.2.3. Miners' Unsafe Behavior Risk Calculation. The paper took the total number of various unsafe behaviors in the fourth quarter of 2018 year of $\mathrm{W}$ mine as the reference sequence $\left(X_{0}^{\prime}\right)$, and the 12 types of unsafe behavior $(A, B, \ldots, L)$ would be taken as the variable sequence $\left(X_{1}^{\prime} X_{2}^{\prime}, X_{3}^{\prime} \ldots X_{12}^{\prime}\right)$.

Find the mean of each sequence, as shown in Table 2.

According to formula (3), each sequence was dimensionalized and the results are shown in Table 3. 


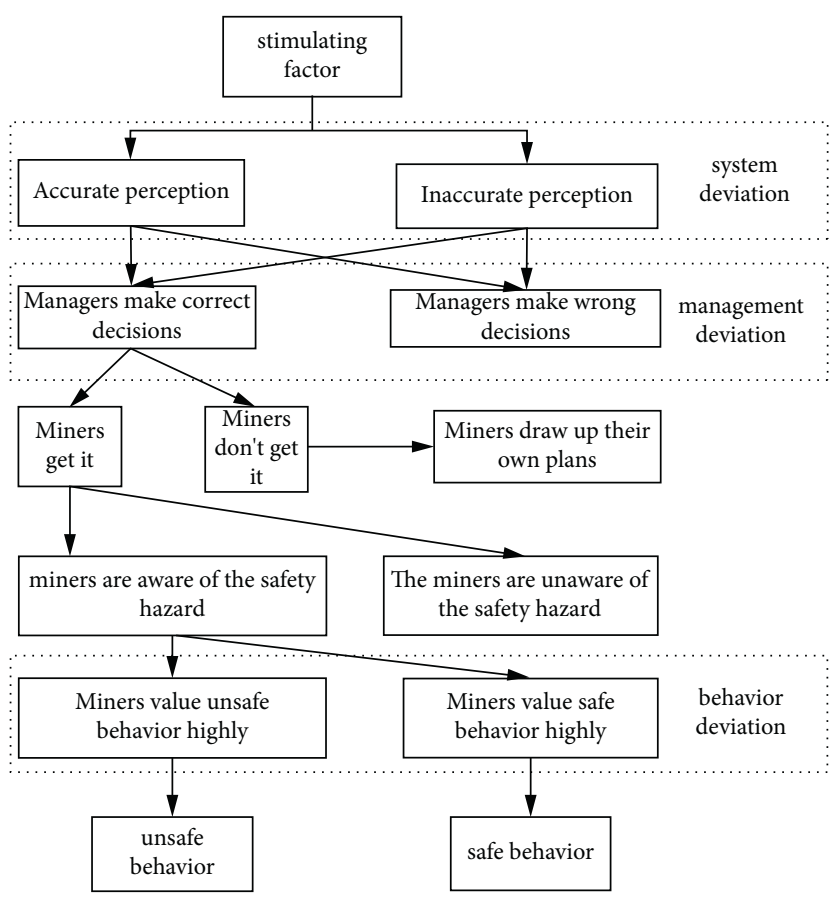

Figure 1: Occurrence mechanism model of unsafe behaviors of coal miner.

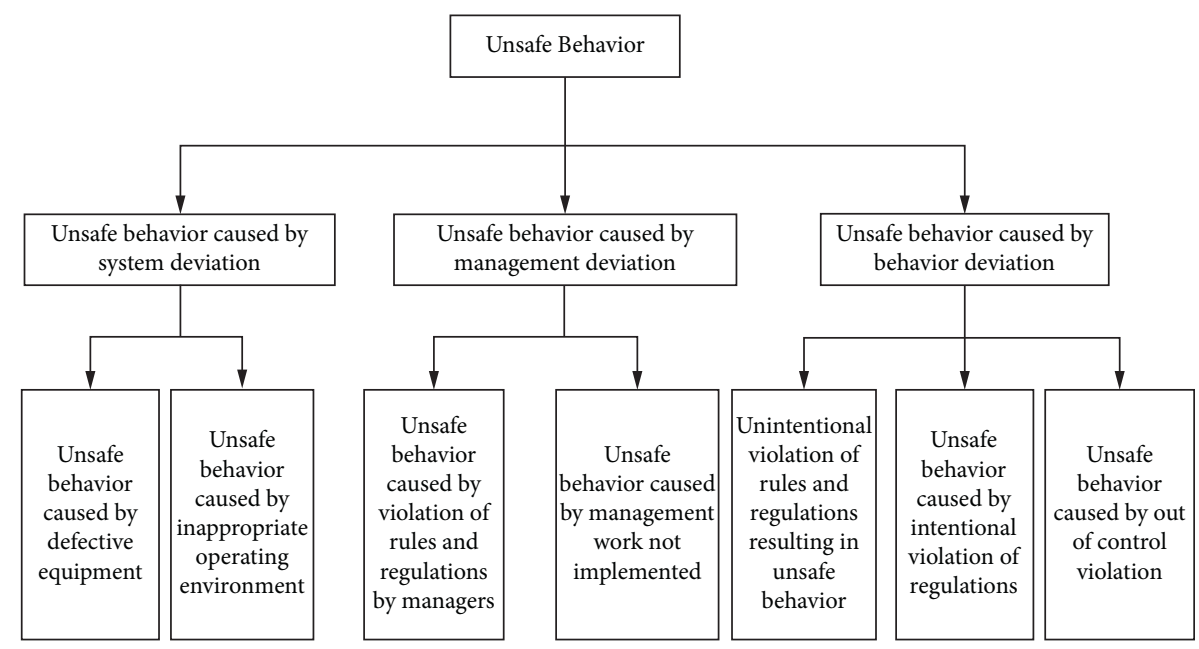

FIgURE 2: Classification of unsafe behaviors.

TAвle 1: Data on miners' unsafe behavior in the fourth quarter of 2019.

\begin{tabular}{|c|c|c|c|c|c|c|c|c|c|c|c|c|c|}
\hline Time & $A$ & $B$ & C & $D$ & E & $F$ & G & $H$ & $I$ & $J$ & K & $L$ & Total \\
\hline $1-10^{\text {th }}$ of January & 1 & 0 & 1 & 1 & 1 & 0 & 2 & 1 & 2 & 0 & 12 & 3 & 23 \\
\hline $11-20^{\text {th }}$ of January & 2 & 0 & 1 & 1 & 0 & 1 & 1 & 0 & 0 & 2 & 10 & 1 & 19 \\
\hline $21-31^{\text {st }}$ of January & 2 & 1 & 4 & 7 & 0 & 1 & 1 & 0 & 0 & 0 & 23 & 6 & 45 \\
\hline $1-10^{\text {th }}$ of February & 6 & 0 & 3 & 0 & 1 & 1 & 1 & 1 & 0 & 2 & 11 & 5 & 31 \\
\hline $11-20^{\text {th }}$ of February & 3 & 1 & 3 & 1 & 1 & 0 & 1 & 1 & 0 & 0 & 15 & 2 & 28 \\
\hline $20-28^{\text {th }}$ of February & 1 & 1 & 3 & 2 & 0 & 1 & 3 & 1 & 0 & 1 & 13 & 2 & 28 \\
\hline $1-10^{\text {th }}$ of March & 3 & 2 & 4 & 2 & 2 & 0 & 1 & 2 & 0 & 0 & 23 & 2 & 41 \\
\hline $11-20^{\text {th }}$ of March & 5 & 1 & 1 & 4 & 0 & 0 & 1 & 1 & 1 & 1 & 5 & 1 & 21 \\
\hline $21-31^{\text {st }}$ of March & 3 & 1 & 6 & 4 & 1 & 0 & 0 & 1 & 2 & 0 & 17 & 2 & 37 \\
\hline Total & 26 & 7 & 26 & 22 & 6 & 4 & 11 & 8 & 5 & 6 & 129 & 24 & 273 \\
\hline Proportion (\%) & 9.52 & 2.56 & 9.52 & 8.06 & 2.20 & 1.47 & 4.03 & 2.93 & 1.83 & 2.20 & 47.25 & 8.79 & 100 \\
\hline
\end{tabular}


Table 2: Miners' unsafe behavior for each sequence mean.

\begin{tabular}{lccccccccccccc}
\hline Sequence & $X_{0}^{\prime}$ & $X_{1}^{\prime}$ & $X_{2}^{\prime}$ & $X_{3}^{\prime}$ & $X_{4}^{\prime}$ & $X_{5}^{\prime}$ & $X_{6}^{\prime}$ & $X_{7}^{\prime}$ & $X_{8}^{\prime}$ & $X_{9}^{\prime}$ & $X_{10}^{\prime}$ & $X_{11}^{\prime}$ & $X_{12}^{\prime}$ \\
\hline Mean & 30.3333 & 2.8889 & 0.7778 & 2.8889 & 2.4445 & 0.6667 & 0.4444 & 1.2222 & 0.8889 & 0.5556 & 0.6667 & 14.3333 & 2.6667 \\
\hline
\end{tabular}

According to formula (5), the absolute differences between the variable sequence and the reference sequence can be obtained. The data are shown in Table 4 after the differential processing.

Two-level minimum absolute difference of each element $\min i \min k \Delta_{i}(k)$ was 0.016099 , and the maximum absolute difference $\max i \max k \Delta_{i}(k)$ was 2.841469 .

According to formula (7), the relational coefficient of unsafe behavior for each variable sequence can be calculated, and the specific value is shown in Table 5 .

According to the gray relational degree of each sequence of unsafe behavior, $K, C$, and $H$ are the three elements with the largest relation with the reference sequence. In other words, these three elements contribute more to the reference sequence in the same order of magnitude. The accident is more severe than other sequences, and the consequences are more serious, causing more damage to coal mines and miners if an accident occurs.

Referring to the definition of risk, the occurrence probability and the severity are multiplied to obtain the risk value of unsafe behavior, as shown in Table 7 .

3.2.4. Results Analysis. According to the above analysis, among the 12 types of unsafe behavior, $\mathrm{K}$, violated labor discipline, has the highest severity and the highest occurrence probability of the unsafe behavior of employees who violated labor discipline. Therefore, the risk value is much higher than other types, being 0.4358 .

It is impossible to completely eliminate the unsafe behaviors of employees if we only pay attention to the unsafe behaviors of employees and use an incident, behavior, and error to explain the causes and conditions of the accident. Meanwhile, all the activities of employees are a concentrated response of a complex system involving organizational and social factors. It has strong adaptability, especially in the increasingly mechanized and automatic system. In order to cope with pressures from corporate profits, production efficiency, social competition, etc., employees must complete a specified amount of work within a specified time, when the unsafe behavior seems to be quite "reasonable" [11]. Therefore, in order to clarify and explain the unsafe behavior of employees, it is necessary to shift the focus of attention from the unsafe behavior itself to the factors forming the employee's behavior.

According to statistics, there are more than 1,500 miners in $\mathrm{W}$ coal mine. The average education level of their personnel is junior high school, as shown in Figure 3. Due to the poor working environment, long working hours, high intensity, and high risk, the age composition of front-line employees in coal mines is mostly concentrated in the 40-50 age group. These miners are generally less educated, but they have rich work experience and some fluke mind; they do not pay attention to learning and promotion in his usual work, so violations of regulations and operations often occur. The relatively young miners can hardly tolerate the hard work of coal mines, so they are highly mobile, which has an impact on the effectiveness of employee training. Therefore, in $\mathrm{W}$ coal mine, the risk value of violating labor discipline is the highest.

\subsection{W Coal Mine Unsafe Behavior Quantity Prediction.}

Any accident is the result of the interaction of hidden dangers in time and space. Hidden dangers are unsafe behaviors of human, unsafe conditions of equipment, and unsafe factors in the environment, which are gray and uncertain $[37,38]$. Therefore, the prediction of the number of unsafe behaviors can be seen as a prediction of gray system. GM $(1,1)$ is simple to calculate and does not require a large number of samples. According to the conclusions drawn in 3.1, among the unsafe behavior data collected in the first quarter of 19 in $\mathrm{W}$ coal mine, violating labor discipline has the highest risk value. The gray prediction model is used to predict the number of unsafe behaviors to help coal mines provide targeted precontrol measures.

As shown in Table 8, the number of violating labor disciplines in the first quarter of 2019 is brought into GM $(1,1)$ to get Table 9 , where the relative error of the prediction model is $24 \%$, mainly because the original data has large oscillations; as shown in Figure 4, the forecasting effect is not ideal. Therefore, in order to improve the prediction accuracy, it is necessary to improve the existing model.

Unsafe behaviors in coal mines are manually identified and input, so the number of unsafe behaviors will fluctuate significantly. In order to weaken the randomness of the sequence, the sequence composed of the mean value of the hidden dangers of every $\mathrm{N}$ consecutive month is regarded as a new gray sequence. That is to say, the initial sequence of unsafe behaviors in (10) is generated by operator $D$ by using the mean value; that is, by the operation of (18) and a new sequence $X^{\prime(0)}(t)$ is obtained:

$$
\begin{aligned}
& X^{\prime(0)}(t)=\left\{x^{\prime(0)}(1) x^{\prime(0)}(2), \ldots x^{\prime(0)}(n-4)\right\}, \\
& x^{\prime(0)}(t)=\frac{1}{4} \sum_{i=t}^{t+4} x^{(0)}(i), \quad t=1,2, \ldots, n-4 .
\end{aligned}
$$

Then, use mean GM $(1,1)$ model for prediction.

Bring the sequence into the optimized prediction model to get Table 10. It is found that after optimization, the prediction accuracy is significantly improved. It can also be seen from Figure 5 that, compared to the original data, the optimized data is smoother. Therefore, it is feasible to use the optimized GM $(1,1)$ to predict the number of unsafe behaviors in the $\mathrm{W}$ coal mine. 


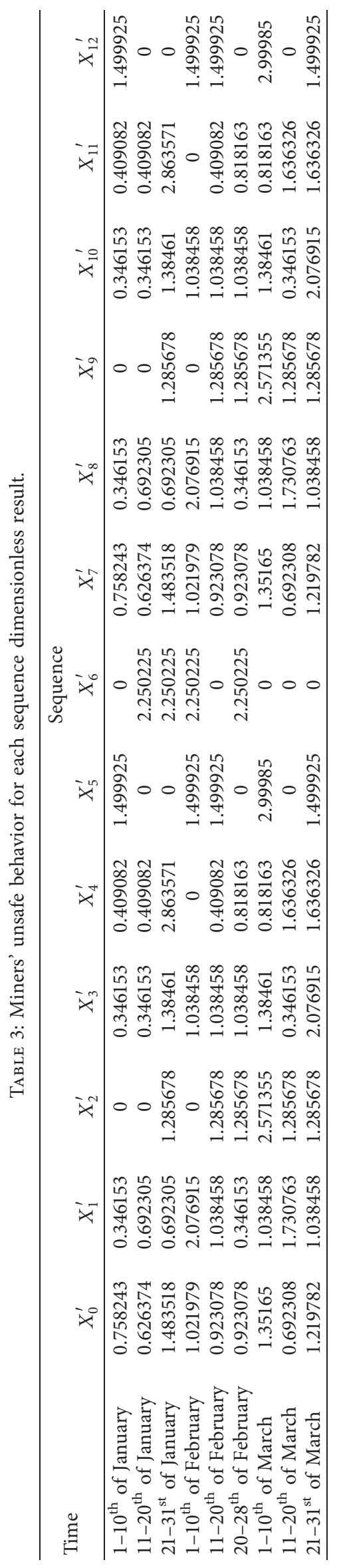


TABLe 4: Miners' unsafe behavior variable sequence absolute differences.

\begin{tabular}{|c|c|c|c|c|c|c|c|c|c|c|c|c|}
\hline \multirow{2}{*}{ Time } & \multicolumn{12}{|c|}{ Absolute differences } \\
\hline & $\Delta_{1}$ & $\Delta_{2}$ & $\Delta_{3}$ & $\Delta_{4}$ & $\Delta_{5}$ & $\Delta_{6}$ & $\Delta_{7}$ & $\Delta_{8}$ & $\Delta_{9}$ & $\Delta_{10}$ & $\Delta_{11}$ & $\Delta_{12}$ \\
\hline $\begin{array}{l}1-10^{\text {th }} \text { of } \\
\text { January } \\
11-20^{\text {th }}\end{array}$ & 0.41209 & 0.758243 & 0.41209 & 0.349161 & 0.741682 & 0.758243 & 0.87815 & 0.366743 & 2.841469 & 0.758243 & 0.078968 & 0.366743 \\
\hline $\begin{array}{l}\text { of } \\
\text { January }\end{array}$ & 0.065931 & 0.626374 & 0.280221 & 0.217292 & 0.626374 & 1.623851 & 0.191823 & 0.626374 & 0.626374 & 2.373476 & 0.071302 & 0.251379 \\
\hline $\begin{array}{l}21-31^{\text {st }} \text { of } \\
\text { January }\end{array}$ & 0.791213 & 0.19784 & 0.098908 & 1.380053 & 1.483518 & 0.766707 & 0.665321 & 1.483518 & 1.483518 & 1.483518 & 0.121137 & 0.766454 \\
\hline $\begin{array}{l}1-10^{\text {th }} \text { of } \\
\text { February } \\
11-20^{\text {th }}\end{array}$ & 1.054936 & 1.021979 & 0.016479 & 1.021979 & 0.477946 & 1.228246 & 0.203782 & 0.103007 & 1.0 & 871 & 535 & 0.852998 \\
\hline $\begin{array}{l}\text { of } \\
\text { February } \\
20-28^{\text {th }}\end{array}$ & 0 & 26 & 8 & 96 & 0.57 & 0.923 & 0.10 & & & 978 & & 0.1 \\
\hline $\begin{array}{l}\text { of } \\
\text { February }\end{array}$ & 0.576925 & 0.3626 & 0.11538 & 0.104915 & 0.923078 & 1.327147 & 1.531512 & 0.201908 & 0.923078 & 0.576847 & 0.016099 & 0.173087 \\
\hline $\begin{array}{l}1-10^{\text {th }} \text { of } \\
\text { March }\end{array}$ & 0.313192 & 1.219705 & 0.03296 & 0.533487 & 1.6482 & 1.35165 & 0.533453 & 0.898322 & 1.35165 & 1.35165 & 0.253005 & 0.601659 \\
\hline $\begin{array}{l}11-20^{\text {th }} \\
\text { of March }\end{array}$ & 1.038455 & 0.59337 & 0.346155 & 0.944018 & 0.692308 & 0.692308 & 0.125889 & 0.432678 & 1.107548 & 0.807617 & 0.34347 & 0.317313 \\
\hline $\begin{array}{l}21-31^{\text {st }} \text { of } \\
\text { March }\end{array}$ & 0.181324 & 0.065896 & 0.857133 & 0.416544 & 0.280143 & 1.219782 & 1.219782 & 0.094796 & 2.37993 & 1.219782 & 0.033733 & 0.469791 \\
\hline
\end{tabular}

TABle 5: Miners' unsafe behavior for each sequence relational coefficient.

\begin{tabular}{|c|c|c|c|c|c|c|c|c|c|c|c|c|}
\hline \multirow{2}{*}{ Time } & \multicolumn{12}{|c|}{ Relational coefficient } \\
\hline & $\xi_{1}$ & $\xi_{2}$ & $\xi_{3}$ & $\xi_{4}$ & $\xi_{5}$ & $\xi_{6}$ & $\xi_{7}$ & $\xi_{8}$ & $\xi_{9}$ & $\xi_{10}$ & $\xi_{11}$ & $\xi_{12}$ \\
\hline $\begin{array}{l}1-10^{\text {th }} \text { of } \\
\text { January } \\
11-20^{\text {th }}\end{array}$ & 0.783945 & 0.659407 & 0.783945 & 0.811818 & 0.664457 & 0.659407 & 0.625013 & 0.803833 & 0.33711 & 0.659407 & 0.958079 & 0.803833 \\
\hline $\begin{array}{l}\text { of } \\
\text { January }\end{array}$ & 0.966481 & 0.701884 & 0.844721 & 0.877174 & 0.701884 & 0.471931 & 0.891028 & 0.701884 & 0.701884 & 0.378691 & 0.963002 & 0.859292 \\
\hline $\begin{array}{l}21-31^{\text {st }} \text { of } \\
\text { January }\end{array}$ & 0.649578 & 0.887715 & 0.945508 & 0.513011 & 0.494734 & 0.656856 & 0.68878 & 0.494734 & 0.494734 & 0.494734 & 0.931876 & 0.656932 \\
\hline $\begin{array}{l}1-10^{\text {th }} \text { of } \\
\text { February }\end{array}$ & 0.580382 & 0.588212 & 0.999736 & 0.588212 & 0.756754 & 0.54241 & 0.884468 & 0.942964 & 0.588212 & 0.422771 & 0.857673 & 0.631927 \\
\hline $\begin{array}{l}11-20^{\text {th }} \\
\text { of } \\
\text { February }\end{array}$ & 0.935369 & 0.805701 & 0.935369 & 0.742653 & 0.719287 & 0.613033 & 0.941806 & 0.88549 & 0.613033 & 0.613033 & 0.930489 & 0.901502 \\
\hline $\begin{array}{l}20-28^{\text {th }} \\
\text { of } \\
\text { February }\end{array}$ & 0.719258 & 0.805701 & 0.935369 & 0.941785 & 0.613033 & 0.522888 & 0.486692 & 0.88549 & 0.613033 & 0.719287 & 0.999999 & 0.901502 \\
\hline $\begin{array}{l}1-10^{\text {th }} \text { of } \\
\text { March }\end{array}$ & 0.828659 & 0.544165 & 0.988401 & 0.735246 & 0.468186 & 0.518266 & 0.735259 & 0.619577 & 0.518266 & 0.518266 & 0.858457 & 0.710462 \\
\hline $\begin{array}{l}11-20^{\text {th }} \\
\text { of March }\end{array}$ & 0.584271 & 0.713386 & 0.813199 & 0.607604 & 0.679983 & 0.679983 & 0.929013 & 0.775237 & 0.568304 & 0.644797 & 0.814437 & 0.826694 \\
\hline $\begin{array}{l}21-31^{\text {st }} \text { of } \\
\text { March }\end{array}$ & 0.896867 & 0.966503 & 0.63078 & 0.782044 & 0.84476 & 0.544149 & 0.544149 & 0.948073 & 0.378048 & 0.544149 & 0.987876 & 0.760018 \\
\hline
\end{tabular}

TABle 6: Miners' unsafe behavior for each sequence gray relational degree.

\begin{tabular}{|c|c|c|c|c|c|c|c|c|c|c|c|c|}
\hline Sequence & $\gamma_{1}$ & $\gamma_{2}$ & $\gamma_{3}$ & $\gamma_{4}$ & $\gamma_{5}$ & $\gamma_{6}$ & $\gamma_{7}$ & $\gamma_{8}$ & $\gamma_{9}$ & $\gamma_{10}$ & $\gamma_{11}$ & $\gamma_{12}$ \\
\hline $\begin{array}{l}\text { Gray } \\
\text { relational } \\
\text { degree }\end{array}$ & 0.771645 & 0.741408 & 0.875225 & 0.733283 & 0.660342 & 0.578769 & 0.747356 & 0.784142 & 0.534736 & 0.555015 & 0.922432 & 0.783574 \\
\hline
\end{tabular}


TABLE 7: The risk value of miners' unsafe behavior.

\begin{tabular}{lccccccccccccc}
\hline Types & $A$ & $B$ & $C$ & $D$ & $E$ & $F$ & $G$ & $H$ & $I$ & $J$ & $K$ \\
\hline Severity & 0.771645 & 0.741408 & 0.875225 & 0.733283 & 0.660342 & 0.5787692 & 0.747356 & 0.784142 & 0.534736 & 0.555015 & 0.922432 & 0.783574 \\
Occurrence probability & $9.52 \%$ & $2.56 \%$ & $9.52 \%$ & $8.06 \%$ & $2.20 \%$ & $1.47 \%$ & $4.03 \%$ & $2.93 \%$ & $1.83 \%$ & $2.20 \%$ & $47.25 \%$ & $8.79 \%$ \\
Risk value & 0.073461 & 0.018980 & 0.083321 & 0.059103 & 0.014528 & 0.008508 & 0.030118 & 0.022975 & 0.009786 & 0.012210 & 0.435849 & 0.068876 \\
\hline
\end{tabular}

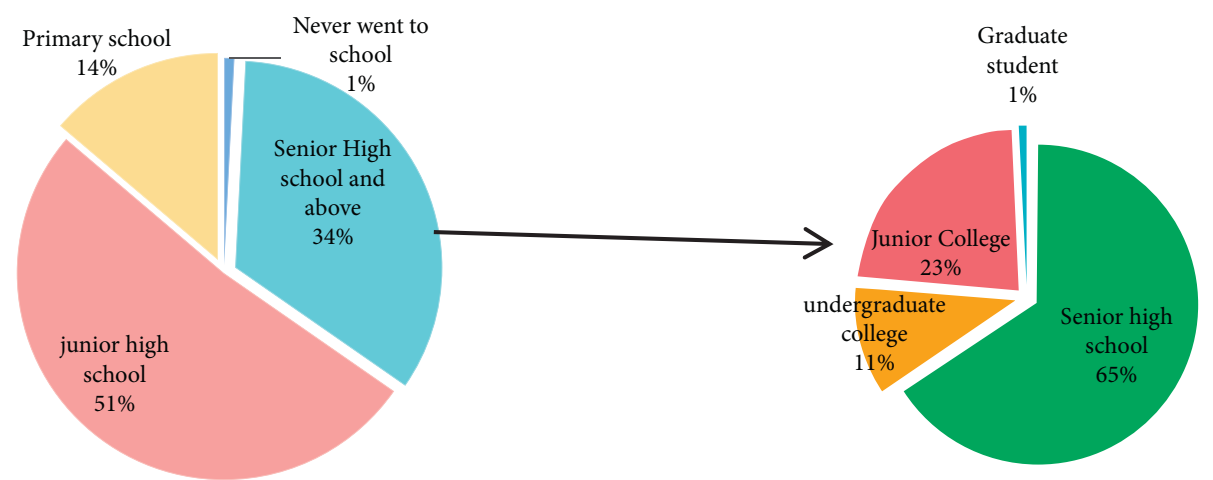

FIgURE 3: The average educational attainment composition of employed persons by W mine from 2005 to 2018.

TABLE 8: Violating labor discipline unsafe behaviors.

\begin{tabular}{|c|c|c|c|c|c|c|c|c|c|c|}
\hline \multirow{2}{*}{ Time } & \multicolumn{3}{|c|}{ January } & \multicolumn{3}{|c|}{ February } & \multicolumn{3}{|c|}{ March } & \multirow{2}{*}{ Tota } \\
\hline & $1-10^{\text {th }}$ & $11-20^{\text {th }}$ & $21-31^{\mathrm{st}}$ & $1-10^{\text {th }}$ & $11-21^{\text {st }}$ & $20-28^{\text {th }}$ & $1-10^{\text {th }}$ & $11-20^{\text {th }}$ & $21-31^{\text {st }}$ & \\
\hline Unsafe behavior quantity & 12 & 10 & 23 & 11 & 15 & 13 & 23 & 5 & 17 & 129 \\
\hline
\end{tabular}

TABLE 9: The GM $(1,1)$ fitted value of original sequence.

\begin{tabular}{lcccc}
\hline No. & Actual value & Fitted value-actual value & Residual error & Relative error \\
\hline 1 & 12 & 12.00 & - & - \\
2 & 10 & 14.90 & 4.90 & 0.49 \\
3 & 23 & 14.82 & -8.18 & -0.36 \\
4 & 11 & 14.74 & 3.74 & 0.34 \\
5 & 15 & 14.66 & -0.34 & -0.02 \\
6 & 13 & 14.58 & 1.58 & -0.12 \\
7 & 23 & 14.50 & -8.50 & -0.37 \\
8 & 5 & 14.42 & 9.42 & -0.168 \\
9 & 17 & 14.34 & -2.66 & -0.16 \\
\hline
\end{tabular}

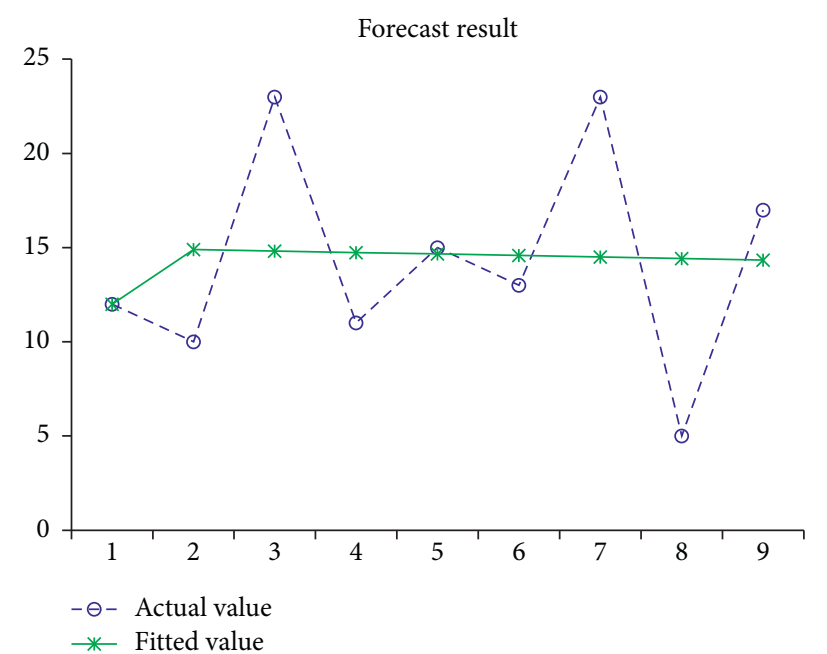

FIGURE 4: The GM $(1,1)$ fitted value of original sequence. 
TABLE 10: The GM $(1,1)$ fitted value of original sequence and buffer operator sequence.

\begin{tabular}{|c|c|c|c|c|c|c|c|c|}
\hline No. & $\begin{array}{c}\text { Actual } \\
\text { value }\end{array}$ & $\begin{array}{c}\text { Fitted value-actual } \\
\text { value }\end{array}$ & $\begin{array}{l}\text { Residual } \\
\text { error }\end{array}$ & $\begin{array}{c}\text { Relative } \\
\text { error }\end{array}$ & $\begin{array}{c}\text { Actual } \\
\text { value }\end{array}$ & $\begin{array}{c}\text { Fitted value-actual } \\
\text { value }\end{array}$ & $\begin{array}{c}\text { Residual } \\
\text { error }\end{array}$ & $\begin{array}{c}\text { Relative } \\
\text { error }\end{array}$ \\
\hline 1 & 12 & 12.00 & - & - & - & - & - & - \\
\hline 2 & 10 & 14.90 & 4.90 & $49 \%$ & - & - & - & - \\
\hline 3 & 23 & 14.82 & -8.18 & $36 \%$ & 20.00 & - & - & - \\
\hline 4 & 11 & 14.74 & 3.74 & $34 \%$ & 17.67 & 15.36 & -2.31 & $13.06 \%$ \\
\hline 5 & 15 & 14.66 & -0.34 & $2 \%$ & 17.00 & 14.19 & -2.81 & $16.53 \%$ \\
\hline 6 & 13 & 14.58 & 1.58 & $12 \%$ & 12.67 & 13.11 & 0.44 & $3.50 \%$ \\
\hline 7 & 23 & 14.50 & -8.50 & $37 \%$ & 12.00 & 12.12 & 0.12 & $1.00 \%$ \\
\hline 8 & 5 & 14.42 & 9.42 & $188 \%$ & 8.67 & 9.56 & 0.89 & $10.31 \%$ \\
\hline 9 & 17 & 14.34 & -2.66 & $16 \%$ & 9.33 & 8.83 & -0.50 & $5.39 \%$ \\
\hline
\end{tabular}

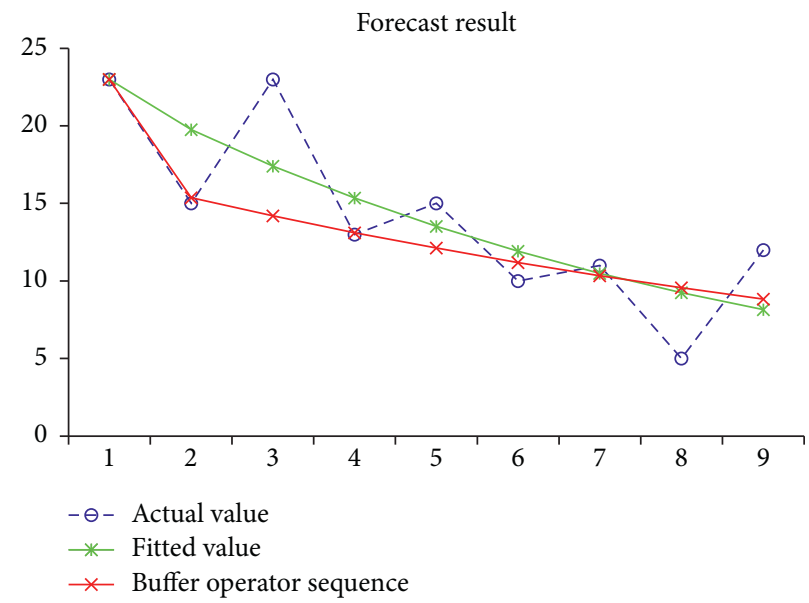

Figure 5: The GM $(1,1)$ fitted value of original sequence and buffer operator sequence.

According to calculations, the number of unsafe behaviors in violation of labor laws and regulations in the second quarter of 2019 in W coal mine is shown in Table 11. The number of unsafe behaviors in the second quarter was 111 , a decrease of $13.95 \%$ from the first quarter.

Comparing the predicted value and the last quarter, the predicted value was down $13.95 \%$ from the last quarter. This is calculated according to the actual situation. However, when determining the control target, coal managers have to consider the actual situation, so the target should be higher than the actual situation.

\section{Unsafe Behavior Control Strategy}

According to the three deviations in the mechanism model of coal miners' unsafe behaviors summarized in the previous article, the formulation of unsafe behavior control measures is mainly about correcting the three deviations.

4.1. The Correcting of System Deviation. First, repair defects in equipment and improve equipment conditions. Improve the safety of equipment; eliminate the dangers of equipment shape, structure, and maintenance; adopt technological transformation and upgrades to make equipment more in line with ergonomic design requirements; strengthen the intrinsic safety of equipment. Second, improve the production environment. The natural conditions of the mine are an objective reality, which basically cannot be changed by itself, but the coal-related production conditions can be changed through technical measures to provide employees with a good production environment. For example, accurately and reasonably control downhole temperature, humidity, lighting intensity, and noise level.

4.2. The Correcting of Management Deviation. First, establish safety culture. Establish safety information dissemination and communication procedures, as well as an unsafe behavior management manual, and formulate corresponding analysis and assessment scoring standards. Second, strengthen safety supervision and inspection. Combine behavior observation methods with safety inspections to formulate scientific and effective supervision and inspection methods. The inspection and rectification are combined, and corresponding rectification measures are proposed based on the inspection results.

4.3. The Correcting of Behavior Deviation. First, strengthen safety education and training. Establish a training platform such as an online training system, formulate a training plan that meets the corporate situation, enrich and improve training content, carry out team risk prediction activities, and assess safety knowledge and skills. Second, improve the safety incentive mechanism. Establish a fair and reasonable reward and punishment system; conduct regular safety 
TABLE 11: Fitted values of violating labor discipline.

\begin{tabular}{|c|c|c|c|c|c|c|c|c|c|c|}
\hline \multirow{2}{*}{ Time } & \multicolumn{3}{|c|}{ April } & \multicolumn{3}{|c|}{ May } & \multicolumn{3}{|c|}{ June } & \multirow{2}{*}{ Tota } \\
\hline & $1-10^{\text {th }}$ & $11-20^{\text {th }}$ & $21-30^{\text {th }}$ & $1-10^{\text {th }}$ & $11-20^{\text {th }}$ & $21-31^{\text {st }}$ & $1-10^{\text {th }}$ & $11-20^{\text {th }}$ & $21-30^{\text {th }}$ & \\
\hline Unsafe behavior quantity & 11 & 10 & 18 & 10 & 13 & 10 & 19 & 5 & 15 & 111 \\
\hline
\end{tabular}

evaluations and establish a complete safety performance evaluation system.

\section{Conclusions}

(1) With the continuous advancement of technology, the reliability of equipment in the production system continues to improve, and human factors are becoming the main factor of production accidents. Data shows that more than $85 \%$ of mine accidents are caused by human factors. Through the analysis of accident cause theory and human accident cause factors, a mechanism model of unsafe behavior of coal miners is obtained. This model has three major deviations from the stimulus factor to the occurrence of the behavior. The three deviations are factors that can lead to unsafe behavior. The first deviation is the deviation of the miner's perception of the system, the second deviation is the deviation of the manager's decision to correct or not, and the third deviation is the deviation of the miner's behavior. According to this model, unsafe behaviors are divided into unsafe behaviors caused by system deviations, those caused by management deviations, and those caused by behavior deviations.

(2) In W mine, a total of 281 pieces of unsafe behavior data were collected in the first quarter of 2019. After excluding invalid data, 273 pieces of valid data were retained. The gray relational analysis was effectively used to calculate risk value of unsafe behavior. Among them, the risk value of violating labor discipline was 0.4358 , which was much higher than other unsafe behaviors and threatened the safety production of coal mine seriously. W coal mine has more than 1500 miners, whose age composition is mainly concentrated in the 40-50 age group. These miners have a low level of education but have certain work experience and fluke mentality, so they often have unsafe behavior. At the same time, because of the strong mobility of miners, the effect of training is not very good. Therefore, in $\mathrm{W}$ coal mine, the unsafe behavior of violating labor discipline has the highest risk value.

(3) In coal mines, information of unsafe behaviors is mainly identified and recorded manually, so data fluctuations are relatively large. Using the GM $(1,1)$ original model to predict the number of unsafe behaviors in violation of labor laws and regulations in the second quarter of 2019 in $\mathrm{W}$ coal mine, the relative error is $24 \%$, and the prediction effect is not good. In order to weaken the randomness of the sequence, the mean value of every three ten-day data is formed into a new gray series. The prediction of the new series has achieved good results, and the relative error has been reduced to $3.36 \%$. Therefore, it is feasible to use the optimized GM $(1,1)$ model to predict unsafe behaviors. By calculation, the predicted number of unsafe behaviors in $\mathrm{W}$ coal mine in the second quarter of 2019 is 111, a decrease of $13.95 \%$ from the first quarter.

\section{Data Availability}

The data used to support the findings of this study are included within the article.

\section{Conflicts of Interest}

The authors declare that they have no conflicts of interest.

\section{Acknowledgments}

This research was supported by the National Natural Science Foundation of China (NSFC) under Grant nos. 51874237 and U1904210.

\section{References}

[1] S. Tian, P. Yang, K. Tang, X. Shen, and F. Shi, "Safety performance of coal mine survey technology using nano-fiber material in coal mining process," Arabian Journal of Geosciences, vol. 13, no. 17, 2020.

[2] X. S. Liu, D. Y. Fan, Y. L. Tan et al., "Failure evolution and instability mechanism of surrounding rock for close-distance chambers with super-large section in deep coal mines," International Journal of Geomechanics, vol. 21, no. 5, Article ID 04021049, 2021.

[3] G. L. Feng, X. T. Feng, B. R. Chen, Y. X. Xiao, and Y. Yu, “A m method for dynamic warning of rockburst development processes in tunnels," Rock Mechanics and Rock Engineering, vol. 48, no. 5, pp. 2061-2076, 2015.

[4] X. Liu, S. Song, Y. Tan et al., "Similar simulation study on the deformation and failure of surrounding rock of a large section chamber group under dynamic loading," International Journal of Mining Science and Technology, vol. 31, no. 3, pp. 495-505, 2021.

[5] G. L. Feng, B. R. Chen, Q. Jiang, Y. X. Xiao, W. J. Niu, and P. X. Li, "Excavation-induced microseismicity and rockburst occurrence: similarities and differences between deep parallel tunnels with alternating soft-hard strata," Journal of Central South University, vol. 28, no. 2, pp. 582-594, 2021.

[6] T. Yang and L. J. Zhou, "Development of early warning control system for unsafe behavior," Safety In Coal Mines, vol. 537, no. 3, pp. 255-258, 2019.

[7] W. Zhang, "Causation mechanism of coal miners' human errors in the perspective of life events," International Journal 
of Mining Science and Technology, vol. 24, no. 4, pp. 581-586, 2014.

[8] J. Rasmussen, "Risk management in a dynamic society: a modeling problem," Safety Science, vol. 27, no. 2/3, pp. 183-213, 1997.

[9] L. J. Wang and Y. L. Wang, Human Reliability Analysis: Human Error Risk Assessment and Control, Beijing Aviation Industry Press, Beijing, China, 2015.

[10] G. J. Fogarty and A. Shaw, "Safety climate and the theory of planned behavior: towards the prediction of unsafe behavior," Accident Analysis \& Prevention, vol. 42, no. 5, pp. 1455-1459, 2010.

[11] R. M. Choudhry, "Behavior-based safety on construction sites: a case study," Accident Analysis \& Prevention, vol. 70, pp. 14-23, 2014.

[12] B. H. W. Guo, Y. M. Goh, and K. L. X. Wong, "A system dynamics view of a behavior-based safety program in the construction industry," Safety Science, vol. 104, pp. 202-215, 2018.

[13] L. Sadeghi, J.-Y. Dantan, L. Mathieu, A. Siadat, and M. M. Aghelinejad, "A design approach for safety based on Product-Service Systems and Function-Behavior-Structure," CIRP Journal of Manufacturing Science and Technology, vol. 19, pp. 44-56, 2017.

[14] H. Wu and D. Fang, "Enhancing the sustainability of BBS implementation in construction psychological and organizational perspectives," Wash D.C, vol. 26, pp. 68-76, 2011.

[15] X. Wang, Y. Xing, L. Luo, and R. Yu, "Evaluating the effectiveness of Behavior-Based Safety education methods for commercial vehicle drivers," Accident Analysis \& Prevention, vol. 117, pp. 114-120, 2018.

[16] H. Li, M. Lu, S. C. Hsu, M. Gray, and T. Huang, "Proactive behavior-based safety management for construction safety improvement," Safety Science, vol. 75, pp. 107-117, 2015.

[17] T. Bhekisipho, "Extracting grey relational systems from incomplete road traffic accidents data: the case of Gauteng province in South Africa," Expert Systems, vol. 31, no. 3, pp. 220-231, 2014.

[18] X. Xia, Z. Wang, and H. Chang, "Grey correlation of vibration with rolling bearing's machining quality[J]," Journal of Aerospace Power, vol. 20, no. 2, pp. 250-254, 2005.

[19] C. Lei, Y. Qin, and R. Deng, "Comparative analysis of the two common methods for skylight measurement based on the ASD spectroradiometer," Tropical Geography, vol. 31, no. 2, pp. 182-186, 2011.

[20] E. C. Chirwa and M. Mingzhi, "Application of grey mod-el $\operatorname{GM}(1,1)$ to vehicle fatality risk estimation," Technological Forecasting and Social Change, vol. 73, no. 5, pp. 588-605, 2006.

[21] C. Czeslaw, "Decomposition of the symptom observation matrix and grey forecasting in vibration condition monitoring of machines," International Journal of Applied Mathematics and Computer Science, vol. 18, no. 4, pp. 569-579, 2008.

[22] H. Yonghong, J. Zhao, H. Li et al., "Karst hydrological processes and grey system model[J]," Journal of the American Water Resources Association, vol. 48, no. 4, pp. 656-666, 2012.

[23] H. Yonghon, C. Bibo, C. Xiang et al., "A piecewise grey system model for study the effects of anthropogenic activities on karst hydrological processes," Water Resources Management, vol. 27, no. 5, pp. 1207-1220, 2013.

[24] S. C. Tian, H. X. Li, L. Wang, and T. Chen, "Probe into the frequency of coal mine accidents based on the theory of three types of hazards," China Safety Science Journal, vol. 17, pp. 177-179, 2007.
[25] Q. X. He, Safety engineering, pp. 111-121, China University of Mining and Technology Press, Xuzhou, China, 2002.

[26] J. L. Deng, Basis of Grey theory, pp. 158-166, Huazhong University of Science and Technology Press, Wuhan, China, 2002.

[27] J. L. Deng, “Control problems of grey system," Systems \& Control Letters, vol. 1, no. 5, pp. 288-294, 1982.

[28] J. L. Deng, "Grey control system," The Journal of Huazhong University of Science and Technology, vol. 1, no. 3, pp. 9-18, 1982.

[29] J. L. Den, "Brief introduction of grey system theory," Inn. Mong. Electr. Power, vol. 3, pp. 51-52, 1993.

[30] S. F. Liu, B. Zeng, J. F. Liu, and N. M. Xie, "Several basic models of GM $(1,1)$ and their applicable bound," Journal of Systems Engineering and Electronics, vol. 3, pp. 501-508, 2014.

[31] S. F. Liu, Y. J. Yang, and L. F. Wu, Grey System Theory and its Application, Science Press, Beijing, China, 2014.

[32] L. Chen, W. Lin, J. Li, B. Tian, and H. Pan, "Prediction of lithium-ion battery capacity with metabolic grey model," Energy, vol. 106, pp. 662-672, 2016.

[33] U. Kumar and V. K. Jain, "Time series models (Grey-Markov, grey model with rolling mechanism and singular spectrum analysis) to forecast energy consumption in India," Energy, vol. 35, no. 4, pp. 1709-1716, 2010.

[34] F. Shaikh, Q. Ji, P. H. Shaikh, N. H. Mirjat, and M. A. Uqaili, "Forecasting China's natural gas demand based on optimised nonlinear grey models," Energy, vol. 140, pp. 941-951, 2017.

[35] H. P. Zhou, The research and application of death rate per million-ton coal prediction method, Ph.D. Thesis, China University of Mining and Technology (Beijing), Beijing, China, 2012.

[36] H. Zhao, Q. He, Z. Wei, and L. Zhou, "Predicting hidden danger quantity in coal mines based on gray nn," Symmetry, vol. 12, no. 4, 2020.

[37] L. K. Wang, The hierarchy analysis for hidden danger and research on early warning method in coal mine, Ph.D. Thesis, China University of Mining and Technology (Beijing), Beijing, China, 2015.

[38] D. Zhang, Studies on the identifification of mine safety hidden danger and the closed-loop management model, Ph.D. Thesis, China University of Mining and Technology, Beijing, China, 2009. 